\title{
THE EFFECT OF SERVICE CONSTRAINT ON EPQ MODEL WITH RANDOM DEFECTIVE RATE
}

\author{
YUNG-FU HUANG
}

Received 22 September 2005; Revised 4 January 2006; Accepted 21 February 2006

Chiu studied the effect of service-level constraint on the economic production quantity (EPQ) model with random defective rate. In this note, we will offer a simple algebraic approach to replace his differential calculus skill to find the optimal solution under the expected annual cost minimization.

Copyright (c) 2006 Yung-Fu Huang. This is an open access article distributed under the Creative Commons Attribution License, which permits unrestricted use, distribution, and reproduction in any medium, provided the original work is properly cited.

\section{Introduction}

The EOQ (economic order quantity) model is widely used by practitioners as a decisionmaking tool for the control of inventory. However, the assumptions of the EOQ model are rarely met. This has led many researchers to study the EOQ extensively under realistic situations. For minimizing the total relevant costs, in most previous all published papers that have been derived using differential calculus to find the optimal solution and the need to prove optimality condition with second-order derivatives, Grubbström and Erdem [4] and Cárdenas-Barrón [1] showed that the formulae for the EOQ and EPQ with backlogging are derived without differential calculus. This algebraic approach could therefore be used easily to introduce the basic inventory theories to younger students. But Ronald et al. [5] thought that their algebraic procedure is too sophisticated to be absorbed by ordinary readers. Hence, Ronald et al. [5] derived a procedure to transform a two-variable problem into two steps, and then, in each step, they solve a one-variable problem using only the algebraic method without referring to calculus. Recently, Chang et al. [2] have rewritten the objective function of Ronald et al. [5] such that the usual skill of completing the square can handle the problem without using their sophisticated method.

Recently, we have studied the paper of Chiu [3] that investigated the effect of servicelevel constraint on the EPQ model with random defective rate using differential calculus to find the optimal solution and the need to prove optimality condition with second-order

Hindawi Publishing Corporation

Mathematical Problems in Engineering

Volume 2006, Article ID 79028, Pages 1-5

DOI 10.1155/MPE/2006/79028 
derivatives. Therefore, in this note, we will offer a simple algebraic approach same as Chang et al. [2] to replace his differential calculus skill. This method can offer another approach to study the basic inventory theories to readers.

\section{Algebraic approach in Chiu's model}

For convenience, we adopt the same notation and assumptions as Chiu [3] in this note.

\section{Notation.}

$Q=$ production lot size in the EPQ model with shortage not permitted,

$Q_{b}=$ production lot size per cycle in the EPQ model with shortage allowed and backordered,

$B=$ allowable backorder level in the EPQ model with backlogging permitted,

$K=$ fixed setup cost for each production run,

$H_{1}=$ maximum level of on-hand inventory in units, when the regular production process stops,

$c=$ production cost per item ( $\$ /$ item, inspection cost per item is included),

$h=$ holding cost per item per unit time (\$/item/unit time),

$b=$ backordering cost per item per unit time,

$c_{s}=$ disposal cost for each scrap item (\$/scrap item),

$T=$ the cycle length,

$t_{1}=$ production uptime,

$t_{2}=$ production downtime,

$t_{3}=$ time shortage permitted,

$t_{4}=$ time needed to satisfy all the backorders by the next production,

$\mathrm{TC}(Q)=$ total inventory costs per cycle in the EPQ model with shortage not permitted,

$\operatorname{TCU}(Q)=$ total inventory costs per unit time in the EPQ model with shortage not permitted,

$\mathrm{TC}\left(Q_{b}, B\right)=$ total inventory costs per cycle in the EPQ model with backlogging permitted,

$\operatorname{TCU}\left(Q_{b}, B\right)=$ total inventory costs per unit time in the EPQ model with backlogging permitted.

2.1. The EPQ model with shortage not permitted. From [3, equation (16)], we know that the expected annual cost, $E[\mathrm{TCU}(Q)]$, can be expressed as

$$
\begin{aligned}
E[\operatorname{TCU}(Q)]= & \lambda\left[\frac{c}{1-E[x]}+c_{s} \frac{E[x]}{1-E[x]}\right]+\frac{K \lambda}{Q} \frac{1}{1-E[x]}+\frac{h Q}{2}\left(1-\frac{\lambda}{P}\right) \frac{1}{1-E[x]} \\
& -h Q\left(1-\frac{\lambda}{P}\right) \frac{E[x]}{1-E[x]}+\frac{h Q}{2} \frac{E\left[x^{2}\right]}{1-E[x]} \\
= & A+\frac{C}{Q}+D Q,
\end{aligned}
$$

where the constants $A=\lambda\left[c /(1-E[x])+c_{s}(E[x] /(1-E[x]))\right], C=K \lambda /(1-E[x])$, and

$$
D=\left(\frac{1}{1-E[x]}\right)\left\{\frac{h}{2}\left(\left(1-\frac{\lambda}{P}\right)+E\left[x^{2}\right]\right)-h\left(1-\frac{\lambda}{P}\right) E[x]\right\} .
$$


Our goal is to find the minimum solution of $E[\operatorname{TCU}(Q)]$ by algebraic approach. Then we rewrite (2.1) as

$$
E[\operatorname{TCU}(Q)]=A+\frac{C}{Q}\left[\sqrt{\frac{D}{C}} Q-1\right]^{2}+2 \sqrt{C D} .
$$

It implies that when

$$
Q^{*}=\sqrt{\frac{C}{D}}=\sqrt{\frac{2 K \lambda}{h(1-\lambda / P)-2 h(1-\lambda / P) E[x]+h E\left[x^{2}\right]}},
$$

then we can get the minimum value of $E[\operatorname{TCU}(Q)]$ as follows:

$$
\begin{aligned}
E\left[\operatorname{TCU}\left(Q^{*}\right)\right]= & A+2 \sqrt{C D}=\lambda\left[\frac{c}{1-E[x]}+c_{s} \frac{E[x]}{1-E[x]}\right] \\
& +2 K \lambda \frac{1}{1-E[x]} \sqrt{\frac{(h / 2)\left((1-\lambda / P)+E\left(x^{2}\right)\right)-h(1-\lambda / P) E(x)}{K \lambda}} .
\end{aligned}
$$

Equation (2.4), in this note, is the same as [3, equation (17)].

2.2. The EPQ model with backlogging. From [3, equation (10)], we know that the expected annual cost, $E\left[\operatorname{TCU}\left(Q_{b}, B\right)\right]$, can be expressed as

$$
\begin{aligned}
E\left[\operatorname{TCU}\left(Q_{b}, B\right)\right]= & \lambda\left[\frac{c}{1-E[x]}+\frac{c_{s} E[x]}{1-E[x]}\right]+\frac{K \lambda}{Q_{b}} \frac{1}{1-E[x]} \\
& +\frac{h}{2}\left[\left(1-\frac{\lambda}{P}\right) Q_{b}-2 B\right] \frac{1}{1-E[x]} \\
& +\frac{B^{2}}{2 Q_{b}} \frac{(b+h)}{1-E[x]} E\left(\frac{1-x}{1-x-\lambda / P}\right) \\
& +h\left[B-\left(1-\frac{\lambda}{P}\right) Q_{b}\right] \frac{E[x]}{1-E[x]}+\frac{h Q_{b}}{2} \frac{E\left[x^{2}\right]}{1-E[x]} \\
= & A+\frac{C}{Q_{b}}+D Q_{b}+\frac{F B^{2}}{Q_{b}}+G B,
\end{aligned}
$$

where the constants $A, C$, and $D$ are the same as before, and the constants $F$ and $G$ are given by

$$
F=\frac{(b+h)}{2(1-E[x])} E\left(\frac{1-x}{1-x-\lambda / P}\right)
$$

and $G=-h$. 
4 The effect of service constraint on EPQ model

Our goal is to find the minimum solution of $E\left[\operatorname{TCU}\left(Q_{b}, B\right)\right]$ by algebraic approach. Then we rewrite (2.6) as

$$
E\left[\operatorname{TCU}\left(Q_{b}, B\right)\right]=A+\frac{C}{Q_{b}}+\frac{F}{Q_{b}}\left[B+\frac{G Q_{b}}{2 F}\right]^{2}+\left[D-\frac{G^{2}}{4 F}\right] Q_{b}
$$

It implies that when $Q_{b}$ is given, we can set $B$ as $B=-(G / 2 F) Q_{b}$ to get the minimum value of $E\left[\operatorname{TCU}\left(Q_{b}, B\right)\right]$ as follows:

$$
E\left[\operatorname{TCU}\left(Q_{b}, B\left(Q_{b}\right)\right)\right]=A+\frac{C}{Q_{b}}+\left[D-\frac{G^{2}}{4 F}\right] Q_{b} .
$$

Then we rewrite (2.9) as

$$
E\left[\operatorname{TCU}\left(Q_{b}, B\left(Q_{b}\right)\right)\right]=A+\left[\sqrt{\left(D-\frac{G^{2}}{4 F}\right) Q_{b}}-\sqrt{\frac{C}{Q_{b}}}\right]^{2}+\sqrt{4 C\left(D-\frac{G^{2}}{4 F}\right)} .
$$

Then we can obtain the optimal production lot size

$$
\begin{aligned}
& Q_{b}{ }^{*} \\
& =\sqrt{\frac{C}{D-G^{2} / 4 F}} \\
& =\sqrt{\frac{2 K \lambda}{h(1-\lambda / P)-h^{2} /(b+h)\left(\{1-E[x]\}^{2}\right) /(E((1-x) /(1-x-\lambda / P)))-2 h(1-\lambda / P) E[x]+h E\left[x^{2}\right]}}
\end{aligned}
$$

and the optimal allowable backorder level

$$
B^{*}=-\frac{G}{2 F} Q_{b}^{*} .
$$

Therefore, the minimum value of the expected annual cost $E\left[\operatorname{TCU}\left(Q_{b}{ }^{*}, B^{*}\right)\right]$ is

$$
\begin{aligned}
& E\left[\operatorname{TCU}\left(Q_{b}{ }^{*}, B^{*}\right)\right] \\
& =A+\sqrt{4 C\left(D-\frac{G^{2}}{4 F}\right)} \\
& =\lambda\left[\frac{c}{1-E[x]}+c_{s} \frac{E[x]}{1-E[x]}\right] \\
& +\sqrt{\frac{2 h K \lambda}{1-E[x]}\left[\frac{(1-\lambda / P)+E\left[x^{2}\right]}{1-E[x]}-2 \frac{(1-\lambda / P) E[x]}{1-E[x]}-\frac{h}{b+h} \frac{1-E[x]}{E((1-x) /(1-x-\lambda / P))}\right]} .
\end{aligned}
$$


Equations (2.11) and (2.12), in this note, are the same as [3, equations (14) and (15)], respectively. Our procedure avoids the differential calculus to find the optimal solution and the need to prove optimality condition with second-order derivatives. We think this method can be easily accepted for readers and may be used to introduce the basic inventory theories to younger students.

\section{References}

[1] L. E. Cárdenas-Barrón, The economic production quantity (EPQ) with shortage derived algebraically, International Journal of Production Economics 70 (2001), no. 3, 289-292.

[2] S. K. J. Chang, J. P. C. Chuang, and H.-J. Chen, Short comments on technical note-The EOQ and EPQ models with shortages derived without derivatives, International Journal of Production Economics 97 (2005), no. 2, 241-243.

[3] Y.-S. P. Chiu, The effect of service level constraint on EPQ model with random defective rate, Mathematical Problems in Engineering 2006 (2006), Article ID 98502, 1-13.

[4] R. W. Grubbström and A. Erdem, The EOQ with backlogging derived without derivatives, International Journal of Production Economics 59 (1999), no. 1-3, 529-530.

[5] R. J. Ronald, G. K. Yang, and P. Chu, Technical note: the EOQ and EPQ models with shortages derived without derivatives, International Journal of Production Economics 92 (2004), no. 2, 197-200.

Yung-Fu Huang: Department of Business Administration, Chaoyang University of Technology, Taichung 41349, Taiwan

E-mail address: huf@mail.cyut.edu.tw 


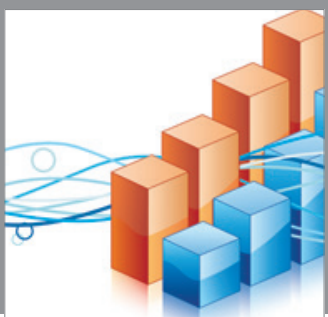

Advances in

Operations Research

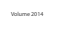

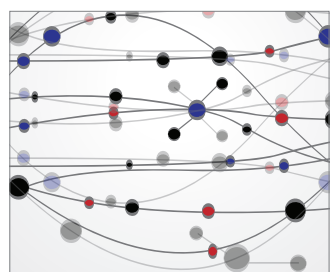

\section{The Scientific} World Journal
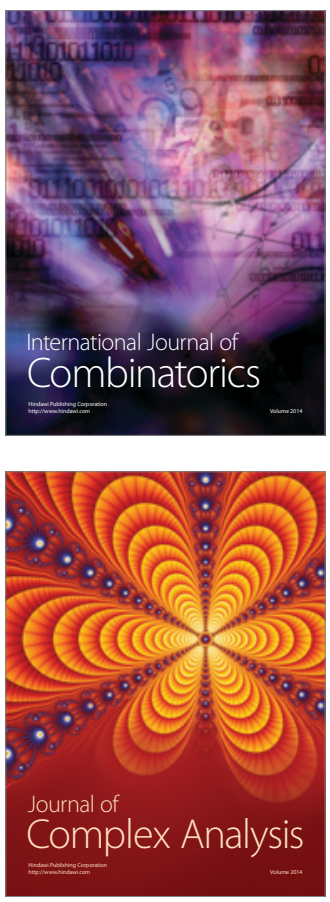

International Journal of

Mathematics and

Mathematical

Sciences
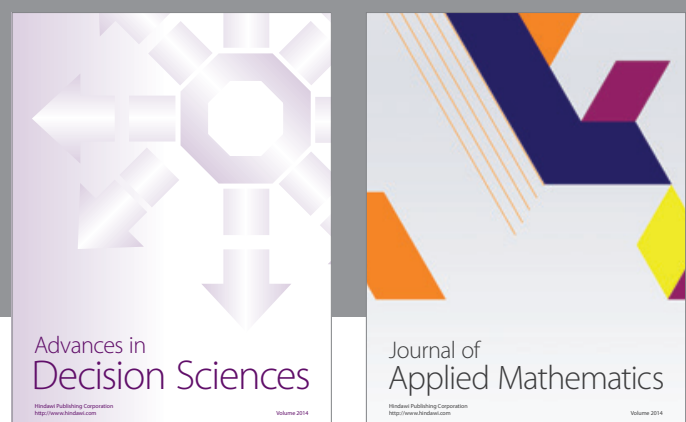

Journal of

Applied Mathematics
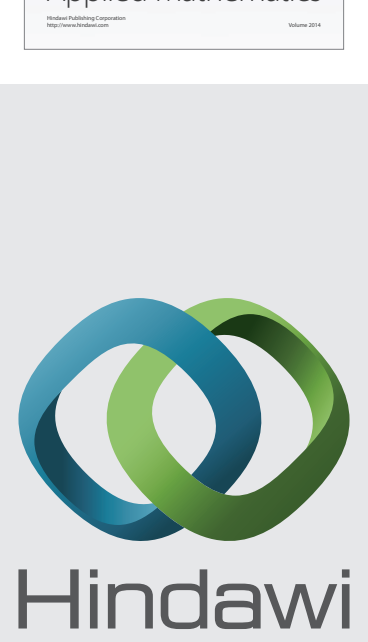

Submit your manuscripts at http://www.hindawi.com
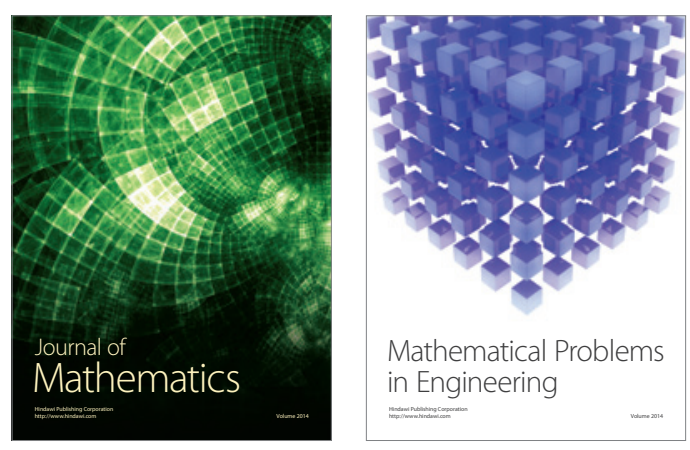

Mathematical Problems in Engineering
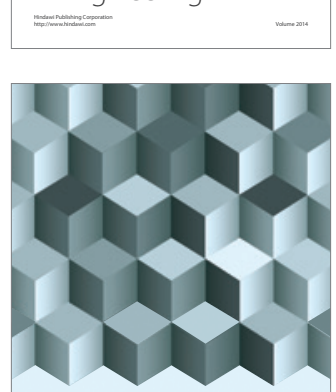

Journal of

Function Spaces
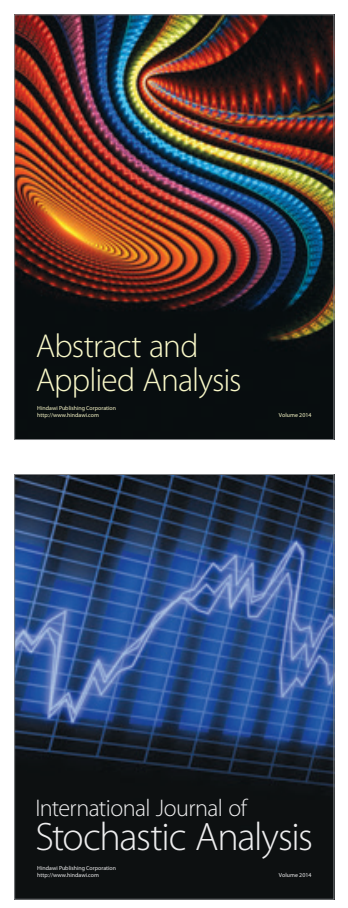

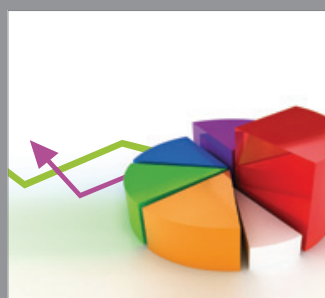

ournal of

Probability and Statistics

Promensencen
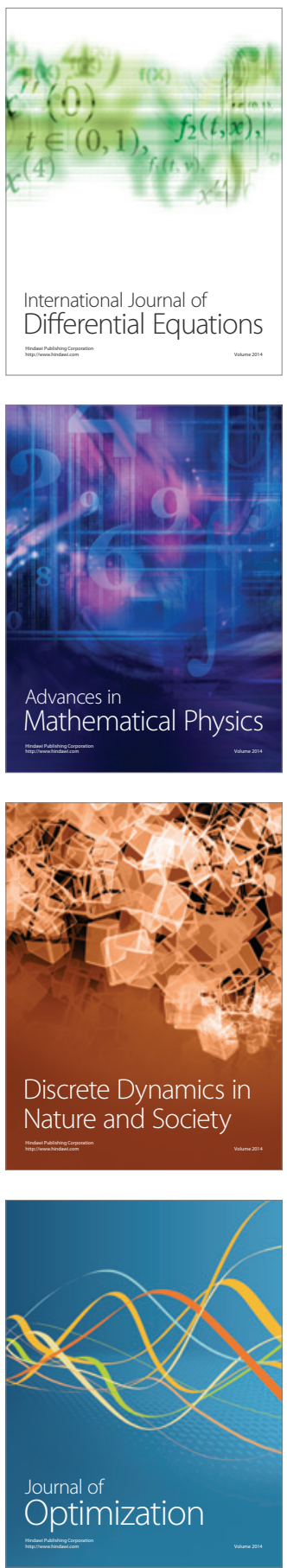